\title{
Penerapan Metode Rapid Application Development (RAD) Dalam Perancangan Media Pembelajaran Multimedia
}

\author{
Ellbert Hutabri \\ Teknik Informatika, Universitas Putera Batam, Jl. R. Soeprapto, Batam, 29437, Indonesia \\ ellbert.hutabri@gmail.com
}

\section{INFORMASI ARTIKEL}

Sejarah Artikel:

Diterima Redaksi:12 September 2019

Revisi Akhir: 09 Oktober 2019

Diterbitkan Online: 14 Oktober 2019

\begin{tabular}{l} 
KATA KUNCI \\
\hline Multimedia, \\
Media Pembelajaran, \\
Rapid Application Development, \\
UML \\
KORESPONDENSI \\
\hline
\end{tabular}

Telepon +6281266364433

E-mail: ellbert.hutabri@gmail.com

\begin{abstract}
A B $\mathbf{S}$ T $\mathbf{R}$ A $\mathbf{C}$ T
Multimedia learning media is one of the learning media used in the teachinglearning process. Based on the results of observations made on simulation subjects and digital communication shows several obstacles in the learning process such as the level of student understanding of subject matter is still low, the level of student activity and the media used are still less varied because the learning process is still fixated with books and not available media multimedia learning in simulation subjects and digital communication. The method used is the RAD (Rapid Application Development) method with object oriented approach and uses UML as a tool for media development. Based on the results of the trial, the designed media can attract the attention of students when learning, and hopefully it can increase the value of students in digital simulation subjects.
\end{abstract}

\section{PENDAHULUAN}

Menengah Kejuruan (SMK) yang bertujuan untuk mengajarkan pada siswa bagaimana menggali ide untuk menyelesaikan suatu masalah terkait produk atau layanan, mencari solusi alternatif dan nyampaikannya dalam bentuk kolaborasi dan sharing sehingga mata pelajaran Simulasi Digital yang disingkat denga simdig menjadi life skill.

Berdasarkan observasi yang dilakukan pada mata pelajaran simdig guru menyampaikan materi terpaku pada buku yang telah diterbitkan oleh Direktorat Pembinaan SMK Kementrian Pendidikan dan Kebudayaan Republik Indonesia kemudian siswa membaca buku tersebut dan melakukan praktikum. Tetapi, pada materi yang bersifat teori guru menyampaikan materi dengan memanfaatkan media power point. Dengan media yang digunakan sekarang ini siswa merasa cepat jenuh karena media yang digunakan dirasa kurang menarik perhatian, sehingga tingkat pemahaman siswa terhadap materi pelajaran masih rendah, tingkat keaktifan siswa masih rendah, serta media yang digunakan masih kurang bervariasi karena dalam proses pembelajaran masih terpaku dengan buku dan belum tersedia media.

Menurut [1] suatu media belum dapat diakatan baik apabila media tersebut tidak dapat digunakan oleh guru dan peserta didik serta berpengaruh terhadap hasil belajarnya. Untuk itu perlu dikembangkan suatu media pembelajaran yang dapat menarik perhatian siswa dalam belajar sehingga tingkat pemahaman siswa menjadi tinggi. Media pembelajaran adalah alat yang dimanfaatkan sebagai perantara guru dengan siswanya dalam menyampaikan suatu ide, gagasan atau materi pembelajaran.

Media pembelajaran merupakan alat dan teknik yang digunakan sebagai perantara komunikasi antara seorang guru dan siswa, yang digunakan dalam rangka mengefektifkan komunikasi dan interaksi antara guru dan siswa dalam proses pembelajaran di sekolah. Media pembelajaran [2] merupakan komponen sumber belajar yang mengandung materi instruksional di lingkungan siswa yang memotivasi siswa untuk belajar.

Perancangan menggunakan metode Rapid Application Development (RAD) merpakan sembuah proses pengebangan software sekuensial linier yang menekankan siklus pengembangan dengan waktu yang singkat sehingga dapat memangkas waktu pengembangan media menadi lebih cepat. Dengan berbantuan UML (Unified Modeling Language) untuk mengkomunikasikan rancangan kedalam bentuk paper based, media ini diharapkan dapat membantu guru dalam memberikan materi simdig yang bersifat teori menjadi lebih menarik, 
siswa dapat belajar secara mandiri karena media dilengkapi dengan materi dan soal latihan. Media yang dirancang diharpkan dapat meningkatkan minat belajar serta hasil belajar siswa.

\section{LANDASAN TEORI}

\subsection{Media}

Media adalah alat penyampaian informasi belajar atau penyampai pesan. Secara khusus, pengertian dalam proses pembelajaran cenderung diartikan sebagai peralatan grafis, fotografis, atau elektronik untuk menangkap, memproses dan menyusun informasi baik secara verbal maupun visual.

Media adalah [3] semua peralatan yang digunakan dalam kegiatan belajar mengajar agar peserta didik lebih mudah memahami materi yang disampaikan oleh guru.

\subsection{Media Pembelajaran}

Pembelajaran pada hakikatnya merupakan proses interaksi antara guru dan siswa, baik interaksi secara langsung seperti kegiatan tatap muka maupun secara tidak langsung, yaitu dengan menggunakan berbagai media pembelajaran. Kegiatan pembelajaran dirancang untuk memberikan pengalaman belajar yang melibatkan proses mental dan fisik melalui interaksi antar peserta didik dengan guru, lingkungan dan sumber belajar lainya dalam rangka pencapaian kompetensi dasar.

Beberapa pendapat para ahli mengenai pembelajaran sebagai berikut:

1. Menurut Hamalik, pembelajaran sebagai suatu kombinasi yang tersusun meliputi unsur manusia, material, fasilitas, perlengkapan, dan prosedur yang saling mempengaruhi untuk mencapai tujuan pembelajaran.

2. Menurut Sudjana, dalam (Rusman, 2017:84-85) mengemukakan pembelajaran dapat diartikan sebagai setiap upaya yang sistematik dan sengaja untuk menciptakan agar terjadi kegiatan interaksi edukatif antara dua pihak, yaitu antara peserta didik (warga belajar) dan pendidik (sumber belajar) yang melakukan kegiatan membelajarkan

Makna pembelajaran lebih bersifat terbuka dalam kaitan dengan proses belajar mengajar, strategi belajar mengajar, dan transfer ilmu pengetahuan kepada siswa. Dalam sistem pembelajaran terdapat seluruh komponen belajar, yaitu guru, murid, bahan ajar, metode belajar mengajar, dan hasil belajar siswa. Proses pembelajaran menekankan pemberian pengalaman langsung untuk mengembangkan kompetensi agar menjelajahi dan memahami bahan ajar secara ilmiah.

Media pebelajaran merupakan alat dan teknik yang digunakan sebagai perantara komunikasi antara seorang guru dan siswa, yang digunakan dalam rangka mengefektifkan komunikasi dan interaksi antara guru dan siswa dalam proses pembelajaran di sekolah. Media pembelajaran [2] merupakan komponen sumber belajar yang mengandung materi instruksional di lingkungan siswa yang memotivasi siswa untuk belajar.

\subsubsection{Fungsi dan Manfaat Penggunaan Media Pembelajaran}

Secara umum, media mempunyai fungsi sebagai berikut:

1. Memperjelas pesan agar tidak terlalu verbalistis.

58 Ellbert
2. Mengatasi keterbatasan ruang, waktu, tenaga dan daya indra.

a) Objek yang terlalu besar, bisa digantikan dengan realita, gambar, film bingkai, film atau model.

b) Objek yang terlalu kecil, dibantu dengan proyektor mikro, film bingkai, atau gambar.

c) Gerak yang terlalu lambat atau terlalu cepat, dapat dibantu dengan timelapse, atau high speed photography.

d) Kejadian atau peristiwa yang terjadi di masa lalu bisa ditampilkan lagi lewat rekaman film, video, film bingkai, foto maupun secara verbal.

e) Objek yang terlalu kompleks (misalnya mesinmesin) dapat disajikan dengan model, diagram.

f) Konsep yang terlalu luas (gunung berapi, gempa bumi, iklim dan lain-lain) dapat divisualisasikan lewat film, gambar dan lain-lain.

3. Menimbulkan gairah belajar, interaksi lebih langsung antara siswa dengan sumber belajar.

4. Memungkinkan anak belajar mandiri sesuai dengan bakat dan kemampuan visual, auditori dan kinestetiknya.

5. Memberi rangsangan yang sama, mempersamakan pengalaman dan menimbulkan persepsi yang sama.

6. Penyampaian pesan pembelajaran dapat lebih berstandar.

7. Pembelajaran dapat lebih menarik.

8. Pembelajaran menjadi lebih interaktif dengan menerapkan teori belajar.

9. Waktu pelaksanaan pembelajaran dapat diperpendek.

10. Kualitas pembelajaran dapat ditingkatkan.

11. Proses pembelajaran dapat berlangsung kapanpun dan dimanapun diperlukan.

12. Sikap positif siswa terhadap materi pembelajaran serta proses pembelajaran dapat ditingkatkan.

Adapun fungsi media pembelajaran bagi pengajar sebagai berikut:

1. Memberikan pedoman, arah untuk mencapai tujuan.

2. Menjelaskan struktur dan urutan pengajaran secara baik.

3. Memberikan kerangkan sistematis mengajar secara baik.

4. Memudahkan kendali pengajar terhadap materi pelajaran.

5. Membantu kecermatan, ketelitian dalam penyajian materi pelajaran.

6. Membangkitkan rasa percaya diri seorang pengajar.

7. Meningkatkan kualitas belajar.

Fungsi media pembelajaran bagi siswa sebagai berikut:

1. Meningkatkan motivasi belajar pembelajaran.

2. Memberikan dan meningkatkan variasi belajar dan pembelajaran.

3. Dapat memberikan struktur materi pelajaran dan memudahkan pembelajar untuk belajar.

4. Memberikan inti informasi, pokok-pokok secara sistematik sehingga memudahkan pembelajar untuk belajar.

5. Merangsang pembelajar untuk berfokus dan beranalisis. 
6. Menciptakan kondisi dan situasi belajar tanpa tekanan.

7. Pembelajar dapat memahami materi pelajaran dengan sistematis yang disajikan pengajar lewat media pembelajaran.

\subsection{Pembelajaran Multi Media}

Multimedia merupakan perpaduan berbagai bentuk elemen informasi yang digunakan sebagai sarana menyampaikan tujuan tertentu. Elemen informasi yang dimaksud tersebut diantaranya teks, grafik, gambar, foto, animasi, audio, dan video. Multimedia adalah gabungan dari berbagai macam media, baik untuk tujuan pembelajaran maupun tujuan yang lain.

Dalam proses belajar mengajar, multimedia berfungsi sebagai penyampai pesan berupa pengetahuan, keterampilan, dan sikap kepada siswa. Pembelajaran dengan multimedia dapat memotivasi pikiran, perasaan, perhatian, dan kemauan belajar siswa. Multimedia pembelajaran merupakan suatu alternatif baru dalam inovasi pembelajaran. Multimedia pembelajaran [2] mampu memadukan pembelajaran dan teknologi. Teknik mengintegrasikan teknologi dan pembelajaran ini dapat memperkuat, melengkapi dan memperluas keterampilan siswa dalam proses pembelajaran .

\subsection{UML (Unified Modeling Language)}

Unified Modeling Language (UML) [7] adalah bahasa pemodelan secara grafis untuk menspesifikasikan, visualisasi, membangun dan mendokumentasikan seluruh artifak sistem perangkat lunak.

\subsubsection{Use Case Diagram}

Use case diagram merupakan diagram untuk menggambarkan aktor eksternal yang berhubungan dengan sistem. Use case menggambarkan sekelompok use cases dan aktor berikut hubungan keduanya serta fungsi yang disediakan oleh sistem dalam bentuk teks sebagai dokumen.

\subsubsection{Activity Diagram}

Activity diagram menggambarkan rangkaian aktivitas sistem dari awal hingga akhir. Digunakan untuk menggambarkan aktifitas yang terjadi dalam suatu operasi sehingga dapat juga digunakan untuk menggambarkan aktifitas atau interaksi lainnya.

\subsubsection{Sequence Diagram}

Mendeskripsikan kolaborasi dinamik antara sejumlah objek untuk menunjukan rangkaian pesan yang dikenal dengan a sequence of message yang dirim dari suatu objek ke objek lainnya.

\section{METODOLOGI}

Pengembangan media ini menggunakan metode RAD (Rapid Application Development) dengan pendekaatan berorientasi objek dan memanfaatkan UML sebagai tools untuk pengembangan media berbasis android. RAD (Rapid Application Development) merupakan siklus hidup untuk pengembangan yang lebih cepat dan mendapatkan hasil dengan kualitas yang lebih baik dari siklus tradisional.
Tahapan RAD [8] terdiri atas perencanaan, analisis, perancangan, implementasi, pengujuan dan peraawatan.

a. Perencanaan

Pada tahap ini dilakukan analisis kebutuhan pengguna yaitu siswa dan guru akan kebutuhan teerhadap media pembelajran interaktif untuk mata pelajaran simdig.

b. Analisis

Analisis dilakukan terhadap standar kompetensi, kompetensi dasar, siswa. Analsis ini bertujuan untuk mendapatkan pemahaman secara keseluruhan terhadap aplikasi yang dirancang agar sesuai dengan karakteristik serta kemampuan siswa.

c. Perancangan

Perancangan dilakukan dengan tujuan untuk mencari solusi terbaik dalam memecahkan suatu masalah. Pada penelitian ini perancangan yang dibuat menggunakan pendekatan berorientasi objek dengan menggunakan UML dalam memvisualkan rancangan media interaktif.

1. Use case diagram

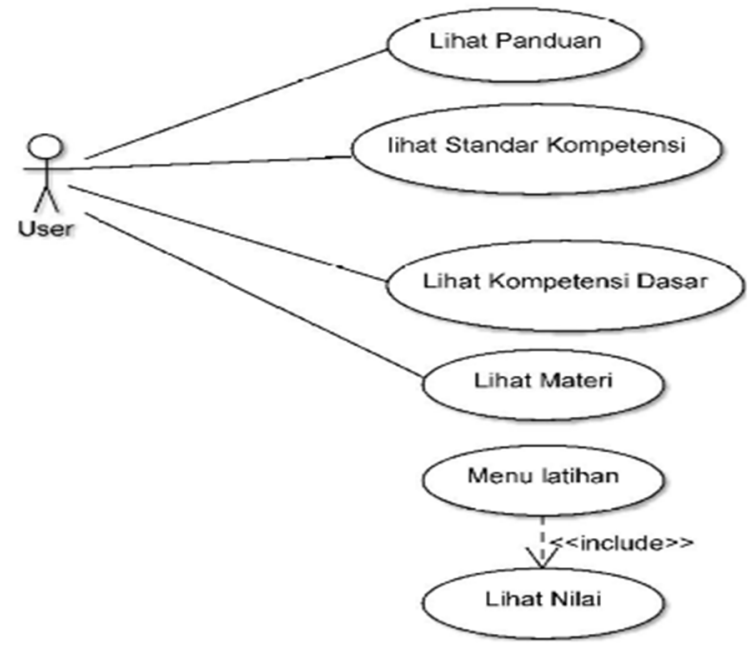

Gambar 1. Use Case Diagram Media Interaktif

Gambar 1 menunjukan hubungan aktor dengan aplikasi media interaktif.

2. Sequence diagram

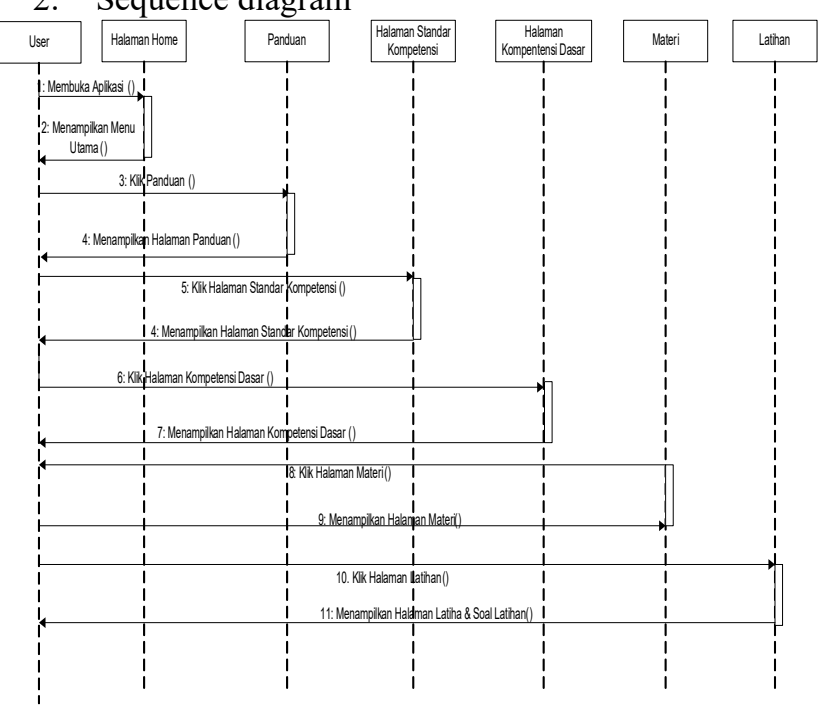

Gambar 2. Sequence Diagram Media Interaktif 
Pada sequence diagram menggambarkan interakasi yang dilakukan oleh aktor yaitu guru dan siswa serta direspon yang diberikan oleh media dengan menampilkan menu yang dipilih, seperti gambar 2 .

3. Activity diagram

Activity diagram menggambarkan urutan kegiatan atau aktivitas yang dilakukan oleh aktor dalam media pembelajaran interaktif.

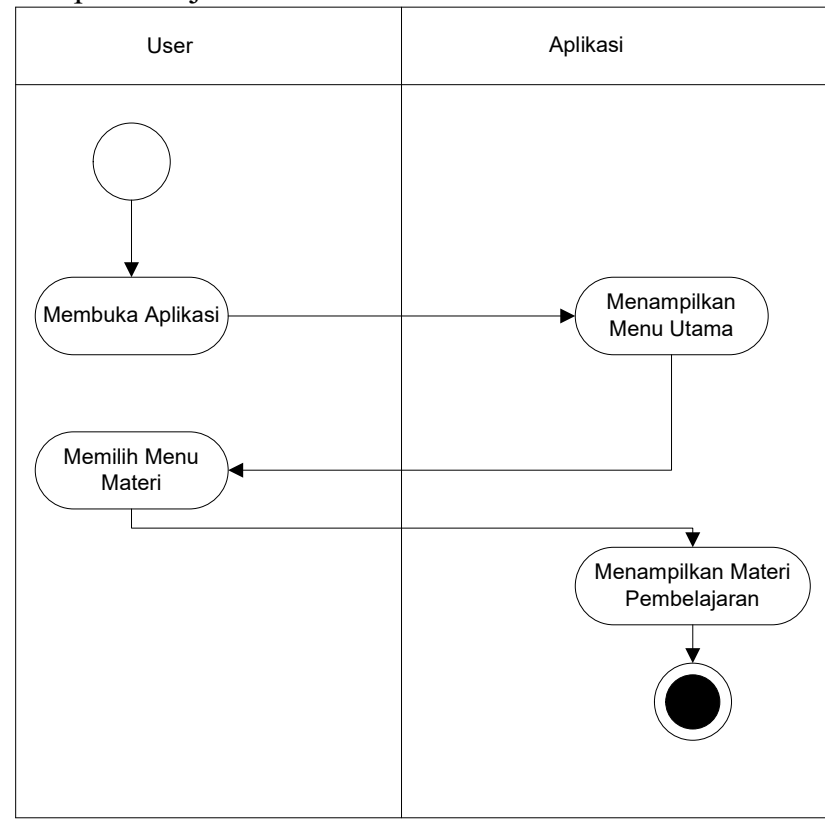

Gambar 3. Activity Diagram Materi Pembelajaran

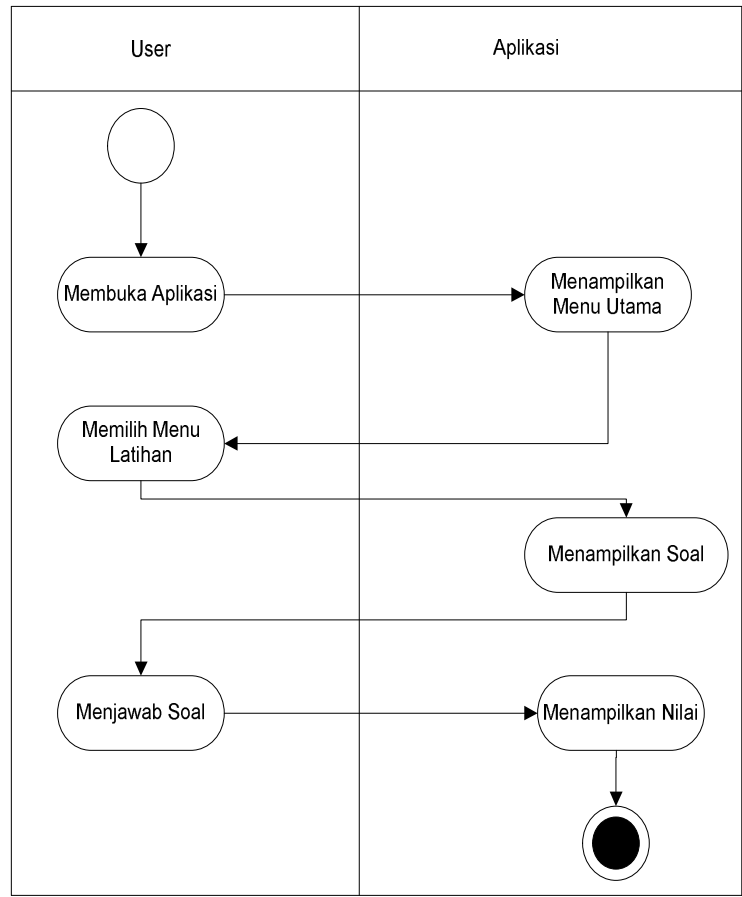

Gambar 4. Activity Diagram Latihan

d. Implementasi

Implementasi menerapkan prinsip-prinsip analisis dan perancangan sistem kedalam suatu bahasa pemrogramran. e. Pengujian

Melakukan pengujian terhadap sistem atau aplikasi yang sudah dirancang kepada end user untuk meminimalkan kesalahan-kesalahan yang terjadi.

f. Perawatan

Merupakan tahap dimana aplikasi yang dirancang telah digunakan dan akan dilakukan perbaikanperbaikan kecil jika ditemukan kesalahan.

\section{HASIL DAN PEMBAHASAN}

Media pembelajaran mulitimedia pada mata pelajaran komunikasi digital yang dikembangkan berisikan materi menganalisis fitur perangkat lunak. Media ini memuat Kompetensi Inti, Kompetensi dasar, Tujuan Pembelajaran, Materi yang memuat gambar, audio, video, kuis. Hasil rancangan media dapat dilihat pada gambar berikut :
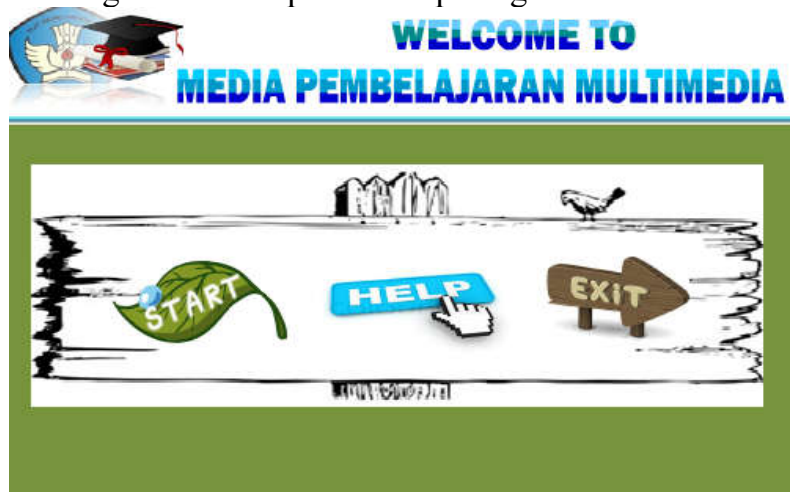

Gambar 5. Tampilan Awal Media Pembelajaran

Gambar 5 menunjukan halaman awal media pembelajaran interaktif yang terdiri dari tiga tombol yaitu Start untuk memulai masuk kemenu utama, Help menu untuk menampilkan petunjuk penggunaan dan exit menu untuk keluar dari media.

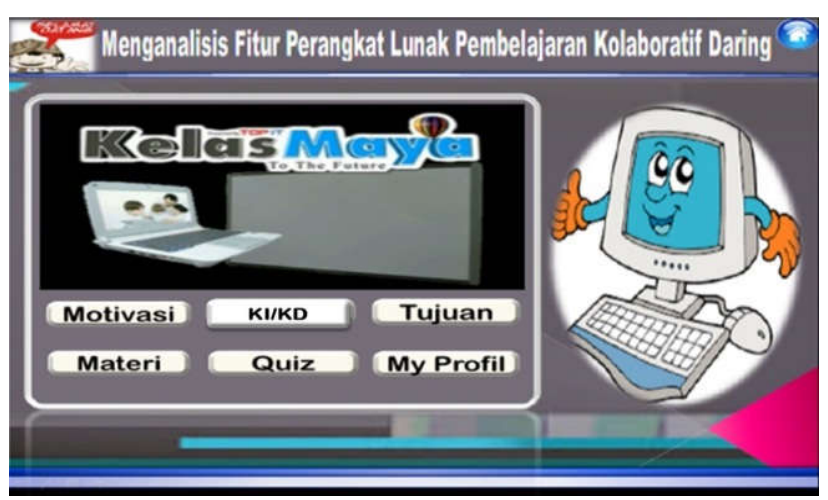

Gambar 6. Halaman Home

Halaman Home merupakan halaman ketika siswa sudah menekan tombol Start. Halaman ini terdiri dari motivasi, KI/KD, Tujuan pembelajaran, Materi, Quis atau latihan dan profile pengembang. 


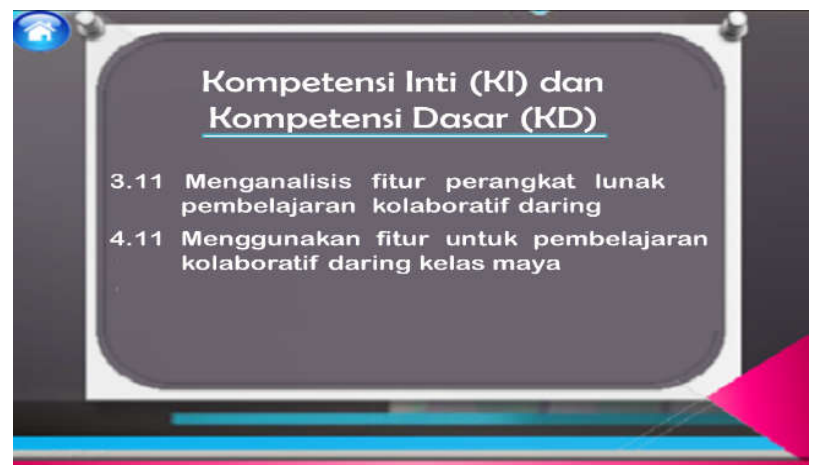

Gambar 7. Halaman Kompetensi Inti (KI) dan Kompetensi Dasar (KD)

Gambar 7 berisi Kompetensi Inti (KI) dan Kompetensi Dasar (KD) yang akan dilakukan dalam proses belajar mengajar.

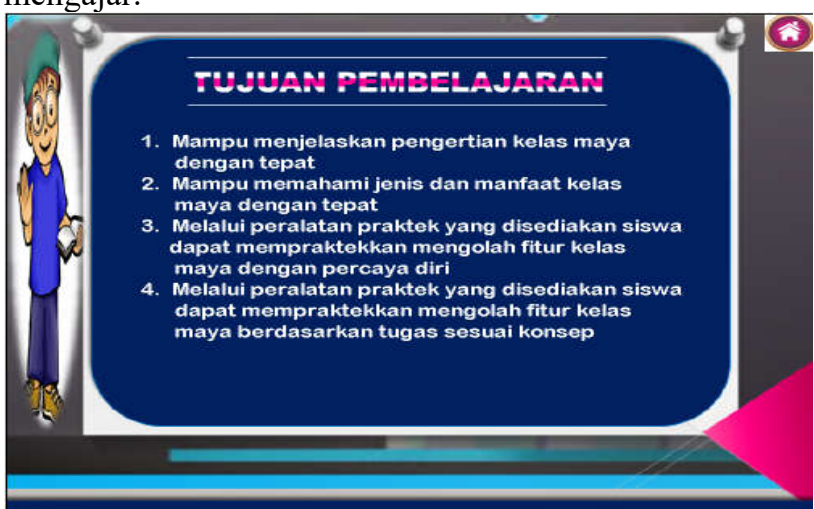

Gambar 8. Tampilan Tujuan Pembelajaran Simulasi dan Komunikasi Digital

Halaman tujuan pembelajaran berisi tujuan-tujuan yang akan dicapai dalam proses belajar mengajar.

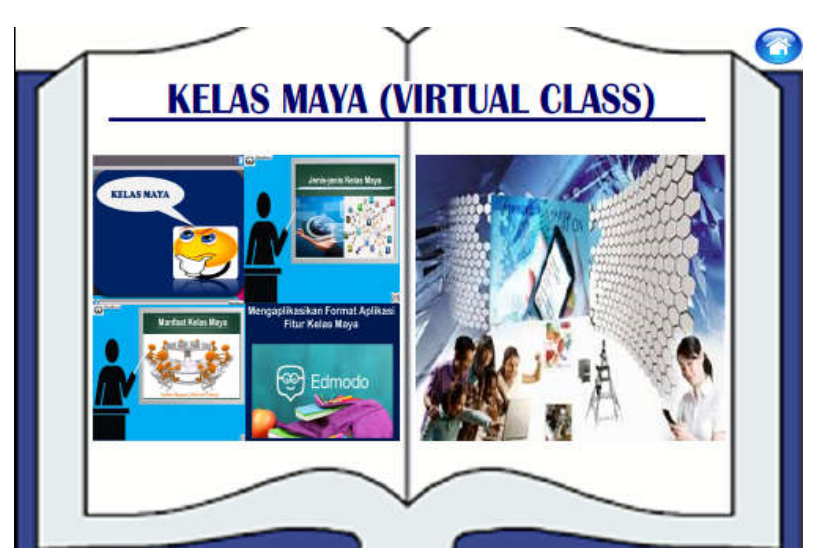

Gambar 6 Tampilan Materi Pelajaran Simulasi dan Komunikasi Digital

Kelas maya (virtual class) merupakan halaman untuk menampilkan materi pembelajaran yang telah disesuaikan dengan materi guru.

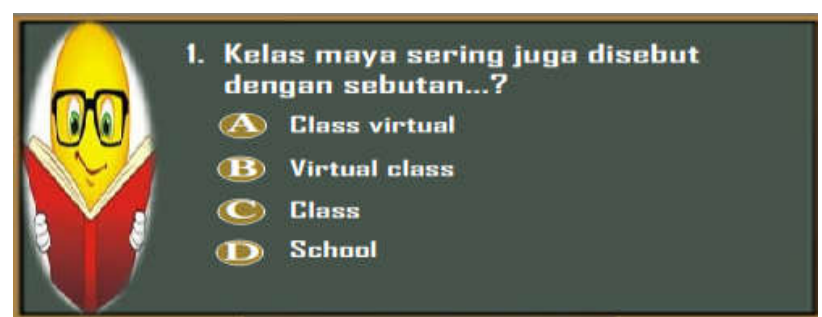

Gambar 10 Tampilan Soal Evaluasi Simulasi dan Komunikasi Digital

Halaman latihan evaluasi merupakan halaman untuk siswa melakukan evaluasi terhadap dirinya sendiri setelah mempelajari materi di class virtual. Setelah selesai melakukan latihan maka siswa dapat langsung melihat nilainya pada halaman nilai yang otomatis muncul setelah menyelesaikan semua jawaban.

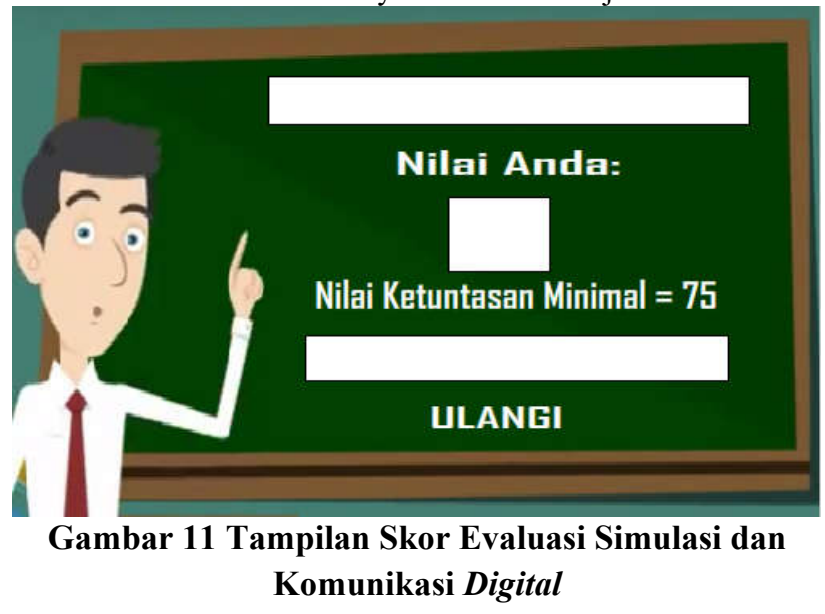

\section{KESIMPULAN}

Berdasarkan hasil uji coba yang telah dilakukan dengan menyebarkan aknget kepada siswa dan guru, diperoleh hasil bahwa siswa merasa sangat tertarik untuk belajar menggunakan media interaktif pada mata pelajaran simulasi digital. Media ini dapat digunakan oleh siswa dengan harapan siswa dapat belajar dan mengevaluasi hasil belajarnya secara mandiri.

\section{DAFTAR PUSTAKA}

[1] A. Alfiriani, E. Hutabri, A. Pratama, P. Studi, and P. Informatika, "Analisis Kebutuhan Belajar Mahasiswa Pada Mata Kuliah Strategi Pembelajaran TI," vol. 2, pp. 1-12, 2017.

[2] E. R. Wati, Ragam Media Pembelajaran Visual, Audio Visual, Komputer, Power Point, Internet, Interactive Video. Kata Pena, 2016.

[3] F. Yasmi, E. Hutabri, and Asril, "Perkembangan peserta didik," in Prosiding Seminar Nasional Biologi Edukasi, 2018, pp. 186-192.

[4] M. P. Dr. Rusman, "Belajar dan Pembelajaran Berorientasi Standar Proses Pendidikan." Kencana, Jakarta, 2017.

[5] M. A. Dr. Hasan Basri, "Paradigma Baru Sistem Pembelajaran.” CV Pustaka Setia, Bandung, 2015.

[6] E. R. Wati, "Ragam Media Pembelajaran." Kata Pena, Jakarta, 2016. 
[7] Y. Heriyanto, "PERANCANGAN SISTEM INFORMASI RENTAL MOBIL BERBASIS WEB PADA PT. APM RENT CAR," J. Chem. Inf. Model., vol. 53, no. 9, pp. 1689-1699, 2013.

[8] Riandy, K. Huliyah, and A. Subiyakto, "Rancang Bangun Sistem Informasi Penjualan Barang ( Studi Kasus: U . D Cendana Depok Townsquare )," Stud. Inform. J. Sist. Inf., vol. 4, no. 1, pp. 1-6, 2011.

\section{BIODATA PENULIS}

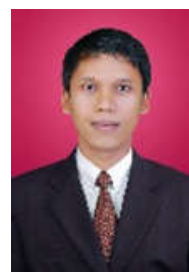

Ellbert Hutabri

Merupakan dosen tetap di Universitas Putera Batam pada program Studi Teknik Informatika. 